\title{
Effect of Body Weight on Pattern of Coronary Lesions in Patients Undergoing Coronary Angiography at Sohag University Hospital
}

\author{
Usama Ahmed Arafa, Hamdy Saad Mohamed, Mohamed Abdel Wahab Ezzat, Ali Badawy Khalaf* \\ Department of Internal Medicine, Faculty of Medicine, Sohag University, Egypt \\ *Corresponding author: Ali Badawy Khalaf Mobile: (+20) 01118380846, E-Mail: dralisalem179@ gmail.com
}

\begin{abstract}
Background: Obesity is related to multiple risk factors of cardiovascular disease (CVD) including hypertension, diabetes mellitus (DM), metabolic syndrome, and dyslipidemia, while also likely being an independent risk factor for CVD. Through multiple pathways including increased angiotensin, circulating blood volume, and total peripheral resistance, excess weight increases hypertension (HTN) risk.

Objective: This study aimed to reveal the relationship between body weight and the severity of coronary artery disease (CAD) in patients referred for coronary angiography at Sohag University Hospital.

Patients and methods: This was a cross-sectional hospital-based study performed on 200 patients, at Sohag University Hospital. Mean age was $56.94 \pm 10.30$ years. Among them, there were 175 patients $(87.5 \%)$ who were overweight or obese with higher prevalence of HTN, hyperlipidemia, and diabetes. Normal weight patients were $25(12.5 \%)$ with lower prevalence of HTN, hyperlipidemia, and diabetes.

Results: According to BMI in our study, 175 patients (87.5\%) were overweight or obese, 162 patients (92.57\%) of the overweight had significant coronary artery disease. 162 patients $(81 \%)$ had significant coronary angiography findings (> 70\% stenosis in any of the coronary arteries). They were classified to 63 patients (31.5\%) had single vessel diseased, 53 patients $(26.5 \%)$ had two vessels diseased, and 46 patients $(23 \%)$ had three vessels diseased.

Conclusion: Obesity, diabetes, hypertension, hyperlipidemia, aging and male gender were correlated with severity of CAD. Thus, reduction of weight, stoppage of smoking and control of diabetes, hypertension and hyperlipidemia will improve outcome of coronary artery disease.
\end{abstract}

Keywords: Body weight, Coronary lesions, Coronary angiography, Obesity.

\section{INTRODUCTION}

Obesity is an independent risk factor for cardiovascular disease (CVD), and is associated with advanced CVD that is associated with percutaneous coronary intervention (PCI), reduction in life expectancy, and a higher mortality rate. Weight loss has been associated with improvement in pre-existing cardiovascular risk factors including hypertension (HTN), diabetes, and dyslipidemia and mortality ${ }^{(\mathbf{1})}$. Obesity is an accepted risk factor for CAD. Therefore, it may be assumed that obese patients have poorer outcomes than non-obese patients ${ }^{(2)}$.

Some studies have reported improved clinical outcomes in overweight and obese patients treated for CVDs compared to normal weight patients, suggesting a paradoxical survival benefit. This effect has been reported in patients with diabetes, end-stage renal disease, HTN, and other conditions traditionally associated with poorer outcomes. Obesity was primarily measured using BMI. The mechanisms leading to this phenomenon, termed "obesity paradox," are unclear ${ }^{(3,}$ ${ }^{4)}$.The quantification of coronary artery disease (CAD) severity can be captured using coronary angiography (CA). Historically CAD has been categorized as single, double, and triple vessel and left main disease, with luminal stenosis of either $\geq 50 \%$ (left main) or $\geq 70 \%$ (other major epicardial vessels) used to define significance $^{(5)}$.

Patients are classified into three categories according to BMI using the World Health Organization classification system: normal $\left(18.5-24.9 \mathrm{~kg} / \mathrm{m}^{2}\right)$, overweight $\left(25.0-29.9 \mathrm{~kg} / \mathrm{m}^{2}\right)$, and obese class (> 30 $\left.\mathrm{kg} / \mathrm{m}^{2}\right)^{(\boldsymbol{6})}$.

The pathogenesis of obesity and atherosclerosis has several common factors. In both cases, lipids, oxidized LDL particles, and free fatty acids activate the inflammatory process and trigger the disease. Inflammation is responsible for all the steps towards atherosclerosis, from early endothelial dysfunction to the atherosclerotic plaques causing complications, and is related to obesity, insulin resistance, and type 2 diabetes. The fatty tissue releases adipocytokines, which induce insulin resistance, endothelial dysfunction, hypercoagulability, and systemic inflammation, thereby facilitating the atherosclerotic process ${ }^{(7)}$.

A $10 \mathrm{~kg}$ rise in body weight increases the risk of coronary artery disease by $12 \%$ and at the same time, systolic blood pressure rises by $3 \mathrm{mmHg}$ and diastolic by $2.3 \mathrm{mmHg}$ as a consequence ${ }^{(\mathbf{8})}$.

This study was conducted to reveal the relationship between body weight and the severity of coronary artery disease in patients referred for coronary angiography at Sohag University Hospital.

\section{PATIENTS AND METHODS}

This was a cross-sectional hospital-based study performed on 200 patients, at Sohag University Hospital-Catheter Lab. Unit.

Inclusion criteria: All patients with coronary artery disease undergoing coronary angiography.

Exclusion criteria: All patients with history of CABG

This article is an open access article distributed under the terms and conditions of the Creative Commons Attribution (CC BY-SA) license (http://creativecommons.org/licenses/by/4.0/) 
or PCI (Since the focus of the study will be on patients with suspected but not yet confirmed CAD).

\section{All patients were subjected to the following:}

1) Full history taking including age, sex, occupation, smoking, exercise, history of diabetes or hypertension and family history of ischemic heart disease.

2) Full clinical examination including weight, height, BMI, waist circumference, skin thickness of the arm, arterial blood pressure and peripheral pulsation.

3) Laboratory investigations including lipid profile, serum creatinine and blood sugar.

4) Electrocardiogram.

5) Echocardiography (using Toshiba, Aplio i900).

6) Coronary angiography (CA).

All patients were hospitalized at Sohag University Hospital- Cath. Lab. Unit. They were screened for overweight and obesity by measuring height, weight, and calculating body mass index (BMI) as part of the routine physical examination. In addition, waist circumference was measured.

Body mass index: Measuring BMI was the generally accepted first step to determine the degree of overweight. The BMI is easy to measure, reliable, and correlated with percentage of body fat and body fat mass. BMI has provided a better estimate of total body fat compared to body weight alone ${ }^{(9)}$.

Calculation of BMI: The BMI is the most practical first step for evaluating the degree of excess weight. It is calculated from the weight and square of the height as follows:

BMI = body weight (in $\mathrm{kg}) \div$ height (in meters) squared.

BMI-based classifications: Body mass index (BMI) classifications are based upon risk of cardiovascular disease (CVD) ${ }^{(\mathbf{1 0})}$. The recommended classifications for BMI adopted by World Health Organization (WHO) ${ }^{(6)}$ for Caucasian, Hispanic, and black individuals are:

Underweight: $<18.5 \mathrm{~kg} / \mathrm{m}^{2}$.

Normal weight: $\geq 18.5$ to $24.9 \mathrm{~kg} / \mathrm{m}^{2}$.

Overweight: $\geq 25.0$ to $29.9 \mathrm{~kg} / \mathrm{m}^{2}$.

Obesity: $\geq 30 \mathrm{~kg} / \mathrm{m}^{2}$.

- Class I: 30.0 to $34.9 \mathrm{~kg} / \mathrm{m}^{2}$.

- Class II: 35.0 to $39.9 \mathrm{~kg} / \mathrm{m}^{2}$.

- Class III: $\geq 40 \mathrm{~kg} / \mathrm{m}^{2}$ (also referred to as severe, extreme, or massive obesity).

Waist circumference: Waist circumference is a measurement of abdominal obesity and provides independent risk information that is not accounted for by BMI (11). In addition to measuring BMI, we suggested measuring waist circumference in overweight and obese adults to assess abdominal obesity. A waist circumference of $\geq(102 \mathrm{~cm})$ for men and $\geq(88 \mathrm{~cm})$ for women; were considered elevated and indicative of increased cardio-metabolic risk ${ }^{(\mathbf{1 2})}$.

Coronary angiography (Assessment for coronary artery atherosclerotic disease): The diagnostic procedure was performed by an experienced interventional cardiologist [using Toshiba infinix CV-I Apparatus Model 2004 (Seldinger's technique)] via right femoral artery after performing local anesthesia with xylocaine.

Patients were grouped according to BMI categories using the World Health Organization classification system into three groups: normal $\left(18.5-24.9 \mathrm{~kg} / \mathrm{m}^{2}\right)$, overweight $\left(25.0-29.9 \mathrm{~kg} / \mathrm{m}^{2}\right)$, and obese class (> $\left.30 \mathrm{~kg} / \mathrm{m}^{2}\right)^{(6)}$.

\section{Ethical consideration:}

The study was aproved by Scientific and Ethical Committees of Sohag Faculty of Medicine. An informed written consent was obtained from every patient. This work has been carried out in accordance with The Code of Ethics of the World Medical Association (Declaration of Helsinki) for studies involving humans.

\section{Statistical analysis}

Data were analyzed using STATA version 14.2 (Stata Statistical Software: Release 14.2 College Station, TX: Stata Corp LP.). Quantitative data were represented as mean, standard deviation, median and range. Data was analyzed using ANOVA for comparison of the means of three groups or more with post-hoc Bonferroni test. When the data were not normally distributed Kruskal Wallis test for comparison of three or more groups. Mann-Whitney test was used to compare two groups. Qualitative data was presented as number and percentage and compared using either Chi square test or fisher exact test. Graphs were produced by using Excel or STATA program. P value was considered significant if it was equal or less than 0.05 .

\section{RESULTS}

- Among 200 patients, 114 patients (57\%) were males and 86 patients $(43 \%)$ were females and mean age was $56.94 \pm 10.30$ years (Table 1$)$.

- Regarding the risk factors, 111 patients $(55.50 \%)$ were diabetic, 127 patients $(63.50 \%)$ were hypertensive, 107 patients $(53.50 \%)$ had history of smoking and 12 patients (6\%) had family history of IHD (Table 2).

- Regarding the risk of hyperlipidemia (patients with LDL level $>70 \mathrm{mg} / \mathrm{dl}$ were considered uncontrolled, all patients were under treatment of statins), 40 patients (20\%) were controlled and 160 patients $(80 \%)$ were uncontrolled (Table 3).

- Regarding BMI, 175 patients $(87.5 \%)$ were overweight or obese: 25 patients $(12.5 \%)$ had normal BMI, 82 patients $(41 \%)$ had a BMI indicating overweight and 93 patients (46.5\%) were classified as obese. According to waist circumference, 24 patients $(12.00 \%)$ were classified as normal waist circumference and176 patients $(88.00 \%)$ were classified as increased waist circumference (central obesity) (Table 4).

- According to coronary angiography (number of vessels diseased), patients were classified according to number of vessels affected into 4 groups, normal group, 
single vessel diseased group, two vessels diseased group and three vessels diseased group. 38 patients $(19 \%)$ had normal angiogram or noncritical $(<70 \%)$ stenosis in any of the coronary arteries, 63 patients $(31.50 \%)$ had single vessel diseased, 53 patients $(26.50 \%)$ had two vessels diseased and 46 patients (23\%) had three vessels diseased (Table 5).

Table (1): Age and gender of studied population

\begin{tabular}{|l|c|}
\hline \multicolumn{1}{|c|}{ Variable } & Summary statistics \\
\hline Age / year & \\
Mean \pm SD & $56.94 \pm 10.3$ \\
Median (range) & $57(25: 87)$ \\
\hline Gender & \\
Females & $86(43 \%)$ \\
Males & $114(57 \%)$ \\
\hline
\end{tabular}

Table (2): Medical history of studied population

\begin{tabular}{|l|c|}
\hline \multicolumn{1}{|c|}{ Variable } & Summary statistics \\
\hline DM & \\
No & $89(44.5 \%)$ \\
Yes & $111(55.5 \%)$ \\
\hline Hypertension & $73(36.5 \%)$ \\
No & $127(63.5 \%)$ \\
Yes & \\
\hline Smoking & $93(46.5 \%)$ \\
No & $92(46 \%)$ \\
Yes & $15(7.5 \%)$ \\
x-smoker & $188(94 \%)$ \\
\hline Family history IHD & $12(6 \%)$ \\
No & \\
Yes & \\
\hline
\end{tabular}

Table (3): Distribution of studied population according to hyperlipidemia

\begin{tabular}{|l|c|}
\hline \multicolumn{1}{|c|}{$\begin{array}{c}\text { Hyperlipidemia } \\
\text { (according level of LDL) }\end{array}$} & $\begin{array}{c}\text { Number } \\
(\mathbf{\%})\end{array}$ \\
\hline Controlled & $40(20 \%)$ \\
Uncontrolled & $160(80 \%)$ \\
\hline
\end{tabular}

Table (4): Anthropometric measures of studied population

\begin{tabular}{|l|c|}
\hline \multicolumn{1}{|c|}{ Variable } & $\begin{array}{c}\text { Summary } \\
\text { statistics }\end{array}$ \\
\hline Waist circumference (cm) & $103.86 \pm 5.62$ \\
Mean \pm SD & $105(85: 114)$ \\
Median (range) & \\
\hline Waist circumference(cm) & $24(12 \%)$ \\
Normal & $176(88 \%)$ \\
Abnormal & $29.52 \pm 3.10$ \\
\hline BMI & 29.74 \\
Mean \pm SD & $(21.13: 36.79)$ \\
Median (range) & \\
\hline BMI group & $25(12.5 \%)$ \\
Normal weight & $82(41 \%)$ \\
Overweight & $93(46.5 \%)$ \\
Obese &
\end{tabular}

Table (5): Number of affected vessels by angiography

\begin{tabular}{|l|c|}
\hline \multicolumn{1}{|c|}{ Number of vessels } & Summary statistics \\
\hline None & $38(19 \%)$ \\
One & $63(31.5 \%)$ \\
Two & $53(26.5 \%)$ \\
Three & $46(23 \%)$ \\
\hline
\end{tabular}

According to risk factors, the 25 normal weight patients were classified to 7 diabetic patients (28\%), 13 hypertensive patients $(52 \%)$ and 1 patients (4\%) with family history of IHD. Regarding risk of hyperlipidemia, there were 24 patients with controlled level of LDL. The 82 overweight patients were classified to 30 diabetic patients $(36.59 \%), 45$ hypertensive patients $(54.88 \%)$ and 7 patients $(8.54 \%)$ with family history of IHD. Regarding hyperlipidemia, there were 66 patients $(80.49 \%)$ with uncontrolled level of LDL. The 93 obese patients were classified into 74 diabetic patients $(79.57 \%), 69$ hypertensive patients (74.19\%) and 4 patients (4.3\%) with family history of IHD. Besides, all obese patients had uncontrolled level of LDL (Tables 6 \& 7).

Table (6): Relation between BMI and medical history

\begin{tabular}{|c|c|c|c|c|}
\hline Variable & $\begin{array}{c}\text { Normal weight } \\
\mathrm{N}=\mathbf{2 5}\end{array}$ & $\begin{array}{c}\begin{array}{c}\text { Overweight } \\
\mathrm{N}=82\end{array} \\
\end{array}$ & $\begin{array}{l}\text { Obese } \\
\mathrm{N}=93 \\
\end{array}$ & $P$ value \\
\hline $\begin{array}{l}\text { DM } \\
\text { No } \\
\text { Yes }\end{array}$ & $\begin{array}{c}18(72 \%) \\
7(28 \%)\end{array}$ & $\begin{array}{l}52(63.41 \%) \\
30(36.59 \%)\end{array}$ & $\begin{array}{l}19(20.43 \%) \\
74(79.57 \%)\end{array}$ & $<0.0001$ \\
\hline \multicolumn{5}{|c|}{$\mathrm{P} 1=0.43, \mathrm{P} 2<0.0001, \mathrm{P} 3<0.0001$} \\
\hline $\begin{array}{c}\text { Hypertension } \\
\text { No } \\
\text { Yes }\end{array}$ & $\begin{array}{l}12(48 \%) \\
13(52 \%)\end{array}$ & $\begin{array}{l}37(45.12 \%) \\
45(54.88 \%)\end{array}$ & $\begin{array}{l}24(25.81 \%) \\
69(74.19 \%)\end{array}$ & 0.01 \\
\hline \multicolumn{5}{|c|}{$\mathrm{P} 1=0.80, \mathrm{P} 2=0.03, \mathrm{P} 3=0.01$} \\
\hline $\begin{array}{c}\text { Family history of IHD } \\
\text { No } \\
\text { Yes } \\
\end{array}$ & $\begin{array}{c}24(96 \%) \\
1(4 \%) \\
\end{array}$ & $\begin{array}{c}75(91.46 \%) \\
7(8.54 \%) \\
\end{array}$ & $\begin{array}{c}89(95.7 \%) \\
4(4.3 \%) \\
\end{array}$ & 0.45 \\
\hline \multicolumn{5}{|c|}{$\mathrm{P} 1=0.45, \mathrm{P} 2=0.95, \mathrm{P} 3=0.25$} \\
\hline
\end{tabular}

$\mathrm{P}$ value compared the three group, P1 compared normal weight with overweight, $\mathrm{P} 2$ compared normal weight with obese, and P3 compared overweight with obese 
Table (7): Relation between hyperlipidemia and BMI

\begin{tabular}{|c|c|c|c|}
\hline BMI & $\begin{array}{c}\text { Controlled } \\
\text { Hyper- } \\
\text { lipidemia } \\
\text { N=40 }\end{array}$ & $\begin{array}{c}\text { Uncontrolled } \\
\text { Hyper- } \\
\text { lipidemia } \\
\text { N=160 }\end{array}$ & P value \\
\hline $\begin{array}{c}\text { Normal } \\
\text { weight }\end{array}$ & $24(96 \%)$ & $1(4 \%)$ & $<0.0001$ \\
$\begin{array}{c}\text { Overweight } \\
\text { Obese }\end{array}$ & $\begin{array}{c}16(19.51 \%) \\
0\end{array}$ & $\begin{array}{c}66(80.49 \%) \\
93(100 \%)\end{array}$ & \\
\hline
\end{tabular}

Data was presented as row percentage

Regarding BMI and coronary angiography results, The 25 (normal weight) patients, $100 \%$ were assigned to normal coronary angiography or non-significant coronary artery stenosis. The 82 (overweight) patients were classified into13 patients $(15.85 \%)$ who had normal coronary angiography or non-significant coronary artery stenosis, 41 patients $(50 \%)$ who had single vessel diseased, 17 patients $(20.73 \%)$ who had two vessels diseased and 11 patients $(13.41 \%)$ who had three vessels diseased. The 93 (obese) patients were classified into 22 patients (23.66) who had single vessel diseased, 36 patients $(38.71 \%)$ who had two vessels diseased and 35 patients (37.63\%) who had three vessels diseased (Table 8).

Table (8): Relation between BMI and number of Vessels affected

\begin{tabular}{|c|c|c|c|c|}
\hline $\begin{array}{l}\text { Number of } \\
\text { vessels }\end{array}$ & $\begin{array}{c}\text { Normal } \\
\text { weight } \\
\mathrm{N}=25\end{array}$ & $\begin{array}{c}\text { Overweight } \\
\mathrm{N}=82\end{array}$ & $\begin{array}{l}\text { Obese } \\
\mathrm{N}=93\end{array}$ & $\begin{array}{c}P \\
\text { value }\end{array}$ \\
\hline None & $\begin{array}{c}25 \\
(100 \%)\end{array}$ & $\begin{array}{c}13 \\
(15.85 \%)\end{array}$ & $\begin{array}{c}0 \\
22\end{array}$ & \multirow{4}{*}{$<0.0001$} \\
\hline One & 0 & $41(50 \%)$ & $(23.66 \%)$ & \\
\hline Two & 0 & $\begin{array}{c}17 \\
(20.73 \%) \\
\end{array}$ & $\begin{array}{c}36 \\
(38.71 \%) \\
\end{array}$ & \\
\hline Three & 0 & $\begin{array}{c}11 \\
(13.41 \%)\end{array}$ & $\begin{array}{c}35 \\
(37.63 \%) \\
\end{array}$ & \\
\hline \multicolumn{5}{|c|}{$\mathrm{P} 1<0.0001, \mathrm{P} 2<0.0001, \mathrm{P} 3<0.0001$} \\
\hline
\end{tabular}

$\mathrm{P}$ value compared the three group, $\mathrm{P} 1$ compared normal weight with overweight, P2 compared normal weight with obese, and P3 compared overweight with obese
Regarding the relation between coronary angiography results and risk factors (age gender and hyperlipidemia) (Tables 9, 10, and 11).

The 200 patients were classified into: 38 patients $(19 \%)$ had normal angiogram or noncritical $(<70 \%)$ stenosis in any of the coronary arteries. They were classified into 20 females (52.63\%) and 18 males $(47.37 \%)$ with mean age of $54.79 \pm 10.17$ years. 11 diabetic patients (28.95\%), 21 hypertensive patients $(55.26 \%), 16$ patients $(42.10 \%)$ with history of smoking and one patient (2.63\%) with family history of IHD. Regarding hyperlipidemia, 33 patients $(94.74 \%)$ had controlled level of LDL and 5 patients $(5.26 \%)$ had uncontrolled level of LDL.

Concerning number of vessels affected: 63 patients (31.5\%) who had single vessel diseased were classified into 24 females (38.10\%) and 39 males (61.90\%) with mean age of $56.94 \pm 9.78$ years. There were 31 diabetic patients (49.21\%), 39 hypertensive patients $(61.90 \%)$, 35 patients $(55.56 \%)$ with history of smoking and two patients $(3.17 \%)$ with family history of IHD. Regarding hyperlipidemia, 7 patients $(17.5 \%)$ had controlled level of LDL and 56 patients (82.5\%) had uncontrolled level of LDL.

53 patients $(26 \%)$ who had two vessels diseased were classified into19 females $(35.85 \%)$ and 34 males $(64.15 \%)$ with mean age of $57.23 \pm 11.36$ years. There were 37 diabetic patients $(69.81 \%), 34$ hypertensive patients $(64.15 \%), 33$ patients $(62.26 \%)$ with history of smoking and 7 patients $(13.21 \%)$ with family history of IHD. Regarding hyperlipidemia, all of them had uncontrolled level of LDL.

46 patients $(23 \%)$ who had three vessels diseased were classified into 23 females (50.00\%) and 23 males $(50.00 \%)$ with mean age of $58.37 \pm 8.55$ years. there were 32 diabetic patients $(69.57 \%), 33$ hypertensive patients $(71.74 \%), 23$ patients $(50.00 \%)$ with history of smoking and 2 patients $(4.35 \%)$ with family history of IHD. Regarding hyperlipidemia, all of them had uncontrolled level of LDL.

Table (9): Relation between number of blood vessels affected and age \& gender

\begin{tabular}{|c|c|c|c|c|c|}
\hline Variable & None $(\mathbf{N}=\mathbf{3 8})$ & One $(\mathbf{N}=63)$ & Two $(\mathbf{N}=\mathbf{5 3})$ & Three (N=46) & P value \\
\hline $\begin{array}{c}\text { Age } / \text { year } \\
\text { Mean } \pm \text { SD }\end{array}$ & $54.79 \pm 10.17$ & $56.94 \pm 9.78$ & $57.23 \pm 11.36$ & $58.37 \pm 8.55$ & 0.44 \\
Median (range) & $54(25: 80)$ & $58(32: 80)$ & $58(35: 87)$ & $58(39: 83)$ & \\
\hline \multicolumn{7}{|c|}{$\mathrm{P} 1=1.00, \mathrm{P} 2=1.00, \mathrm{P} 3=0.6, \mathrm{P} 4=1.00, \mathrm{P} 5=1.00, \mathrm{P} 6=1.00$} & \\
\hline Gender & $20(52.63 \%)$ & $24(38.1 \%)$ & $19(35.85 \%)$ & $23(50 \%)$ & 0.25 \\
Females & $18(47.37 \%)$ & $39(61.9 \%)$ & $34(64.15 \%)$ & $23(50 \%)$ & \\
Males & $\mathrm{P} 1=0.15, \mathrm{P} 2=0.11, \mathrm{P} 3=0.81, \mathrm{P} 4=0.80, \mathrm{P} 5=0.22, \mathrm{P} 6=0.16$ & \\
\hline \multicolumn{7}{|c|}{}
\end{tabular}

$\mathrm{P}$ value compared the four group, $\mathrm{p} 1$ compared none with one, $\mathrm{p} 2$ none with two, $\mathrm{p} 3$ none with three, $\mathrm{p} 4$ one with two, p5 one with three, p6 two with three. 
Table (10): Relation between number of blood vessels affected and medical history

\begin{tabular}{|c|c|c|c|c|c|}
\hline Variable & $\begin{array}{l}\text { None } \\
\mathrm{N}=38 \\
\end{array}$ & $\begin{array}{c}\text { One } \\
\mathrm{N}=63 \\
\end{array}$ & $\begin{array}{c}\text { Two } \\
\mathrm{N}=53 \\
\end{array}$ & $\begin{array}{l}\text { Three } \\
\mathrm{N}=46\end{array}$ & P value \\
\hline DM & & & & & \multirow{3}{*}{$<0.0001$} \\
\hline No & $27(71.05 \%)$ & $32(50.79 \%)$ & $16(30.19 \%)$ & $14(30.43 \%)$ & \\
\hline Yes & $11(28.95 \%)$ & $31(49.21 \%)$ & $37(69.81 \%)$ & $32(69.57 \%)$ & \\
\hline \multicolumn{6}{|c|}{$\mathrm{P} 1=0.045, \mathrm{P} 2<0.0001, \mathrm{P} 3<0.0001, \mathrm{P} 4=0.03, \mathrm{P} 5=0.03, \mathrm{P} 6=0.98$} \\
\hline Hypertension & & & & & \multirow{3}{*}{0.47} \\
\hline No & $17(44.74 \%)$ & $24(38.1 \%)$ & $19(35.85 \%)$ & $13(28.26 \%)$ & \\
\hline Yes & $21(55.26 \%)$ & $39(61.9 \%)$ & $34(64.15 \%)$ & $33(71.74 \%)$ & \\
\hline \multicolumn{6}{|c|}{$\mathrm{P} 1=0.51, \mathrm{P} 2=0.39, \mathrm{P} 3=0.12, \mathrm{P} 4=0.80, \mathrm{P} 5=0.28, \mathrm{P} 6=0.42$} \\
\hline Smoking & & & & & \multirow{4}{*}{0.36} \\
\hline No & $22(57.89 \%)$ & $28(44.44 \%)$ & $20(37.74 \%)$ & $23(50 \%)$ & \\
\hline Yes & $15(39.47 \%)$ & $28(44.44 \%)$ & $30(56.6 \%)$ & $19(41.3 \%)$ & \\
\hline $\mathrm{X}$-smoker & $1(2.63 \%)$ & $7(11.11 \%)$ & $3(5.66 \%)$ & $4(8.7 \%)$ & \\
\hline \multicolumn{6}{|c|}{$\mathrm{P} 1=0.21, \mathrm{P} 2=0.16, \mathrm{P} 3=0.46, \mathrm{P} 4=0.34, \mathrm{P} 5=0.82, \mathrm{P} 6=0.31$} \\
\hline Family history & & & & & \multirow{3}{*}{0.08} \\
\hline No & $37(97.37 \%)$ & $61(96.83 \%)$ & $46(86.79 \%)$ & $44(95.65 \%)$ & \\
\hline Yes & $1(2.63 \%)$ & $2(3.17 \%)$ & $7(13.21 \%)$ & $2(4.35 \%)$ & \\
\hline
\end{tabular}

$\mathrm{P}$ value compared the four group, $\mathrm{p} 1$ compared none with one, $\mathrm{p} 2$ none with two, $\mathrm{p} 3$ none with three, $\mathrm{p} 4$ one with two, p5 one with three, p6 two with three.

Table (11): Relation between hyperlipidemia and number of blood vessels affected

\begin{tabular}{|c|c|c|c|}
\hline $\begin{array}{c}\text { Number of affected } \\
\text { vessels }\end{array}$ & $\begin{array}{c}\text { No hyperlipidemia } \\
\mathbf{N}=\mathbf{4 0}\end{array}$ & $\begin{array}{c}\text { Hyperlipidemia } \\
\mathbf{N = 1 6 0}\end{array}$ & P value \\
\hline None & $33(82.5 \%)$ & $5(3.13 \%)$ & \\
One & $7(17.5 \%)$ & $56(35 \%)$ & $<0.0001$ \\
Two & 0 & $53(33.13 \%)$ & \\
Three & 0 & $46(28.75 \%)$ & \\
\hline
\end{tabular}

\section{DISCUSSION}

Our study examined the relationship between BMI and $\mathrm{CAD}$ in patients undergoing $\mathrm{CA}$ for suspected, but not yet confirmed CAD.

Our study was performed on 200 patients with mean age of $56.94 \pm 10.30$ years. Among them, 175 patients $(87.5 \%)$ were overweight or obese with higher prevalence of HTN, hyperlipidemia, and diabetes. Normal weight patients were $25(12.5 \%)$ with lower prevalence of HTN, hyperlipidemia, and diabetes. These findings are supported by the study of Labounty et al. (13). The relationship between obesity and prevalence of diabetes, systemic hypertension and hyperlipidemia was also reported by Labounty $\boldsymbol{e t}$ al. ${ }^{(13)}$ who mentioned that a higher BMI was independently associated with increased risk of MI. In the current study we found strong relation between obesity and the modifiable risk factors of CAD (diabetes, systemic hypertension and hyperlipidemia).

Obesity is an independent risk factor for both DM and Metabolic Syndrome, with the prevalence of DM being closely related to the rise in obesity ${ }^{(14)}$. The Behavioral risk Factor Surveillance System demonstrated that the prevalence of DM increased 33\% throughout follow up, a rise related with increasing rates of obesity ${ }^{(15)}$. DM increases the risk of CAD through its association with endothelial dysfunction and dyslipidemias, both initial steps in the atherogenic process. Through these mechanisms, DM is one of the strongest $\mathrm{CAD}$ risk factors, characterized by very high 10-year risk of CV events ${ }^{(16)}$.

All patients in our study; underwent coronary angiography at Sohag University Hospital-Cath. Lab. Unit. By comparison between findings of coronary angiography and the BMI of all patients, we found that 175 patients $(87.5 \%)$ were overweight or obese, 162 patients $(92.57 \%)$ of them had significant coronary artery disease. Also, 162 patients $(81 \%)$ had abnormal significant coronary angiography findings (> 70\% stenosis in any of the coronary arteries) where they were classified into 63 patients $(31.5 \%)$ had single vessel diseased, 53 patients $(26.5 \%)$ had two vessels diseased, and 46 patients (23\%) had three vessels diseased. Similar study by Gregory $\boldsymbol{e t}$ al. ${ }^{(\mathbf{1 7 )}}$ compared between CAD and obesity. It was performed on 8079 patients in Memorial University of New foundland, St. John's, NL, Canada 2017. There were 6782 patients $(83.95 \%)$ who were overweight or obese; 3898 patients $(57.48 \%)$ of them had significant coronary artery disease.

Regarding male gender as a risk factor for CAD in our study, we found that there were 114 male patients in our study; 96 of them $(84.21 \%)$ had significant coronary artery disease varied from single vessel to three vessels diseased. In contrast of female gender, there were 86 female patients, 66 of them $(76.744 \%)$ had significant coronary artery disease, almost of them were postmenopause. In study of Gregory et $\boldsymbol{a l} .{ }^{(17)}$, there were 4669 patients $(57.79 \%)$ who had significant coronary 
artery disease, 5074 were male patients $(62.8 \%)$. In study of Baghbani-Oskouei et al. ${ }^{(18)}$, there were 185 patients of significant coronary artery disease, 123 patients $(66.5 \%)$ were males. From the results above, we found increase in prevalence of CAD in male patients.

Regarding aging as a risk factor for CAD in our study, we found that the mean age of 200 patients was $56.94 \pm 10.30$ years and there were 162 patients $(81 \%)$ who had significant coronary artery disease. This is in agreement with Gregory et al. ${ }^{(17)}$ who reported that the mean age of 8079 patients was $61.2 \pm 10.6$ years and 4669 patients $(57.79 \%)$ had significant coronary artery disease. Niraj et al. (19) reported that 720 patients $(57.79 \%)$ had significant coronary artery disease and the mean age was $60.6 \pm 10.5$ years. From the results above we found increase in prevalence of CAD with aging.

Regarding diabetes, systemic hypertension and hyperlipidemia as risk factors for CAD in our study, there were 111 patients $(55.5 \%)$ who had type II diabetes, 100 patients $(90 \%)$ of them had significant coronary artery disease. There were 127 hypertensive patients, 106 patients $(83.464 \%)$ of them had significant coronary artery disease. There were 160 patients $(80 \%)$ with uncontrolled level of LDL, 155 patients $(96.88 \%)$ of them who had significant coronary artery disease. There were 107 patients $(53.5 \%)$ with history of smoking, 91 patients $(85.05 \%)$ of them had significant coronary artery disease. These results are similar to that of Gregory et al. ${ }^{(17)}$ where 6782 patients (83.95\%) were overweight or obese, 3898 patients $(57.48 \%)$ of them had significant coronary artery disease and 1917 patients $(28.3 \%)$ of them had type II diabetes, 4499 patients $(66.34 \%)$ of them were hypertensive and 5455 patients $(80.43 \%)$ of them had hyperlipidemia. In Niraj et al. ${ }^{(19)}$ study, 618 patients $(80.26 \%)$ were overweight or obese, 585 patients $(81.25 \%)$ of them had significant coronary artery disease, 230 patients $(37.21 \%)$ of them had type II diabetes, 436 patients $(70.6 \%)$ of them were hypertensive, and 380 patients $(61.45 \%)$ of them had hyperlipidemia. In Baghbani-Oskouei et al. (18) study, there were 185 patients of significant coronary artery disease, 39 patients $(21 \%)$ of them were diabetic and 156 patients $(84 \%)$ were hypertensive.

Obesity's relationship with HTN has been well described in the literature in large studies. Wilson et al. (20) demonstrated that $34 \%$ of HTN in men and $62 \%$ of HTN in women aged 35-75 years was attributable to excess weight (defined as a BMI $\geq 25 \mathrm{~kg} / \mathrm{m}^{2}$ ). Gelber $\boldsymbol{e t}$ al. ${ }^{(21)}$ reported $8 \%$ increase in risk of incidence of HTN with each 1-unit increase in BMI during a median follow-up of 14.5 years. Weight loss on the other hand, decreases the risk of HTN. An analysis of Moore et al. (22) demonstrated that sustained weight loss of $1.8 \mathrm{~kg}$ or more was associated with a long-term HTN risk reduction of $22 \%$ in middle-aged patients and a $26 \%$ reduction in older patients.
CAD is an important preventable health problem as many of its risk factors are modifiable. Modifications of risk factors of $\mathrm{CAD}$ are the most important interventions to reduce morbidity and mortality of CAD. CAD risk factors are classified into modified (e.g., diabetes, high blood pressure, smoking, obesity, etc.) and unmodified (e.g., age and genetic factors). Prevalence of CAD increases along with increasing prevalence of its risk factors ${ }^{(23)}$. Reduction of CAD was tried by primary and secondary prevention strategies; primary prevention as behavioral changes and risk factors modifications (24). Meanwhile, secondary prevention of CAD is an important objective; it leads to reduction of cardiac events especially acute $\mathrm{MI}{ }^{(\mathbf{2 5})}$.

\section{CONCLUSION}

Obesity, diabetes, hypertension, hyperlipidemia, aging and male gender were correlated with severity of CAD. Thus, reduction of weight, stoppage of smoking and control of diabetes, hypertension and hyperlipidemia will improve outcome of coronary artery disease. Due to CAD high expenses of treatment and their complications, appropriate approach, prevention, and treatment lead to save economic resources and health costs. Awareness to $\mathrm{CAD}$ risk factors will result in achieving prevention, control, and stability. These achievements lead to lowering of risk factors, treatment expenses, and improving quality of life and eventually minimize illnesses and disabilities.

\section{Financial support and sponsorship: Nil. Conflict of interest: Nil.}

\section{REFERENCES}

1. Flegal K, Kit B, Orpana $H$ et al. (2013): Association of all-cause mortality with overweight and obesity using standard body mass index categories: a systematic review and meta-analysis. The Journal of the American Medical Association, 309: 71-82.

2. Jensen M, Ryan D, Apovian C,et al. (2013): 2013 AHA/ACC/TOS Guideline for the Management of Overweight and Obesity in Adults: A Report of the American College of Cardiology/American Heart Association Task Force on Practice Guidelines and The Obesity Society. J Am Coll Cardiol., 129: 102-38.

3. Kalantar-Zadeh K, Streja E, Molnar M et al. (2012): Mortality prediction by surrogates of body composition: an examination of the obesity paradox in hemodialysis patients using composite ranking score analysis. American Journal of Epidemiology, 175: 793-803.

4. Roger V, Go A, Lloyd-Jones D et al. (2011): Heart disease and stroke statistics - 2011update: a report from the American Heart Association. Circulation, 125: 2220.

5. Ringqvist I, Fisher L, Mock M et al. (1983): Prognostic value of angiographic indices of coronary artery disease from the Coronary Artery Surgery Study (CASS). Journal of Clinical Investigation, 71: 18541866. 
6. World Health Organization (2000): Obesity: Preventing and Managing the Global Epidemic, World Health Organization, Geneva, Switzerland, Pp: 252. https://apps.who.int/iris/handle/10665/42330

7. Shirzad M, Karimi A, Dowlatshahi S et al. (2009): Relationship between body mass index and left main disease: the obesity paradox. Archives of Medical Research, 40: 618- 624.

8. Esposito K, Pontillo A, di Palo C et al. (2003): Effect of weight loss and lifestyle changes on vascular inflammatory markers in obese women: a randomized trial. JAMA., 289: 1799-1804.

9. Mei Z, Grummer-Strawn L, Pietrobelli A et al. (2002): Validity of body mass index compared with other body-composition screening indexes for the assessment of body fatness in children and adolescents. Am J Clin Nutr., 75: 978-82.

10. Whitlock G, Lewington $S$, Sherliker $P$ et al. (2009): Body-mass index and cause-specific mortality in 900 000 adults: collaborative analyses of 57 prospective studies. Lancet, 373: 1083-96.

11. Gnatiuc L, Alegre-Díaz J, Wade $\mathrm{R}$ et al. (2019): General and Abdominal Adiposity and Mortality in Mexico City: Prospective Study of 150000 Adults. Ann Intern Med., 19: 1-20.

12. Johnson A, Parlow J, White $M$ et al. (2015): Body mass index, outcomes, and mortality following cardiac surgery in Ontario, Canada. Journal of the American Heart Association, 4: 2140-45.

13. Labounty T, Gomez M, Achenbach S et al. (2013): Body mass index and the prevalence, severity, and risk of coronary artery disease: an international multicentre study of 13874 patients. European Heart JournalCardiovascular Imaging, 14: 456-463.

14. Todd Miller M, Lavie $C$, White $C$ (2008): Impact of obesity on the pathogenesis and prognosis of coronary heart disease. Journal of the Cardiometabolic Syndrome, 3 (3): 162-7.

15. Fox C, Pencina M, Meigs J et al. (2006): Trends in the incidence of type 2 diabetes mellitus from the 1970s to the 1990s: the Framingham Heart Study. Circulation, 113 (25): 2914-8.
16. Haffner $S$, Lehto $S$, Ronnemaa $T$ et al. (1998): Mortality from coronary heart disease in subjects with type 2 diabetes and in nondiabetic subjects with and without prior myocardial infarction. The New England Journal of Medicine, 339 (4): 229-34.

17. Gregory A, Lester K, Gregory D et al. (2017): The relationship between body mass index and the severity of coronary artery disease in patients referred for coronary angiography. Cardiology Research and Practice, 17: 5481671.

18. Baghbani-Oskouei A, Gholampourdehaki M (2020): Anthropometric measures and the risk of coronary artery disease. Caspian Journal of Internal Medicine, 11: 183-190.

19. Niraj A, Pradhan J, Fakhry H et al. (2007): Severity of coronary artery disease in obese patients undergoing coronary angiography: obesity paradox revisited. Clinical Cardiology, 30: 391-396.

20. Wilson P, D'Agostino R, Sullivan L et al. (2002): Overweight and obesity as determinants of cardiovascular risk: the Framingham experience. Archives of Internal Medicine, 162 (16): 1867-72.

21. Gelber R, Gaziano J, Manson J et al. (2007): A prospective study of body mass index and the risk of developing hypertension in men. American Journal of Hypertension, 20 (4): 370-7.

22. Moore L, Visioni A, Qureshi M et al. (2005): Weight loss in overweight adults and the long-term risk of hypertension: the Framingham study. Archives of Internal Medicine, 165 (11): 1298-303.

23. Gupta S, Gupta V, Gupta R et al. (2012): Prevalence of risk factors in CAD patients. J Preventive Cardiol., 1: 164-72.

24. Khayyam-Nekouei Z, Yousefy A, Khayyam-Nekouei A et al. (2009): The relation between anxiety and quality of life in heart patients. Health Inf Manage, 5 (1): 19-24.

25. Yousefy A, Khayyam-Nekouei Z, Manshaee G (2012): Cognitive-behavioral therapy and quality of life: An experience among cardiac patients. J Edu Health Promot., 1: 1-4. 